\section{Revista}

Ibero-Americana

de Estratégıa

\title{
APRENDIZAGEM E ADEQUAÇÃO DAS OPERAÇÕES PARA REALIZAR ESTRATÉGIAS DE EXPORTAÇÃO EM MICRO E PEQUENAS EMPRESAS
}

LEARNING AND FITNESS FOR PERFORMING OPERATIONS EXPORT STRATEGIES IN SMEs

\section{APRENDIZAJE Y ADECUACIÓN DE LAS OPERACIONES PARA LOGRAR ESTRATEGIAS DE EXPORTACIÓN EN LAS PYMES}

\section{Teodoro Malta Campos}

Mestre em Administração pela Universidade Nove de Julho - UNINOVE

Professor universitário concomitante com as atividades de coach organizacional para empresários, executivos e empreendedores

E-mail: teodoro@gruposerintegral.com.br (Brasil)

\section{Edmilson de Oliveira Lima}

Doutor em Administração pela HEC Montreal, Canadá

Professor no Programa de Mestrado e Doutorado em Administração da Universidade Nove de Julho

- UNINOVE/PMDA

E-mail: edmilsonolima@gmail.com (Brasil) 


\section{APRENDIZAGEM E ADEQUAÇÃO DAS OPERAÇÕES PARA REALIZAR ESTRATÉGIAS DE EXPORTAÇÃO EM MICRO E PEQUENAS EMPRESAS}

\section{RESUMO}

Esse artigo apresenta um estudo do desenvolvimento tecnológico que ocorre em associação aos processos de aprendizagem em micro e pequenas empresas exportadoras de frutas. Seu objetivo é responder a seguinte pergunta: Como as MPEs fruticultoras adequam suas operações para realizar a estratégia de exportação? Para buscar respostas, foi realizada uma pesquisa qualitativa de estudo multicaso, sendo estudadas quatro empresas. Os dados foram obtidos com o uso de entrevistas semiestruturadas e em profundidade. Para assegurar a qualidade das exportações de frutas, existe um selo de certificação internacional denominado Globalgap, que, depois de obtido, possibilita a superação de barreiras de entrada dos produtos em outros países. Três das quatro empresas estudadas possuem a certificação. Ao longo do processo de certificação, as empresas tiveram de promover intensa aprendizagem e mudanças em suas rotinas de trabalho. Essas mudanças implicaram na utilização de novas tecnologias, como no caso do modo e do tipo de aplicação de fertilizantes e defensivos químicos. Com a aprendizagem, ocorreram processos como aquisição de novos conhecimentos sobre técnicas de manejo agrícola mais apropriadas para produzir frutas de melhor qualidade, conscientização sobre a necessidade de maior cuidado na higiene pessoal e treinamento em primeiros socorros. A análise dos dados permitiu concluir que, para realizarem a estratégia de exportação, as empresas tiveram de buscar desenvolvimento tecnológico e aprimoramento de sua mão de obra, tendo como ganho secundário a melhoria dos processos produtivos, inclusive para as frutas que são direcionadas ao mercado brasileiro, que também obtiveram melhoria de qualidade.

Palavras-chave: Estratégia em Micro e Pequenas Empresas; Exportação de Frutas; Processo de Aprendizagem.

\section{LEARNING AND FITNESS FOR PERFORMING OPERATIONS EXPORT STRATEGIES IN SMES}

\section{ABSTRACT}

This article presents a study of the technological development that occurs in association with learning processes in SMEs of fruits growers. The goal of the article is to answer the following question: How do SMEs of fruits growers conduct their operations to fit the strategy of export? To seek answers, we performed a qualitative multi-case study, four companies being studied. Data were collected using semi-structured interviews. To ensure the quality of fruit exports, there is an international certification called GLOBALGAP which, once obtained, makes it possible to overcome barriers of entry for products into other countries. Three of the four companies studied are certified. Throughout the certification process, the companies had to promote learning and intense changes in their daily work. These changes involved the use of new technologies, such as mode and type of application of chemical fertilizers and pesticides. With the learning process came the acquisition of new knowledge about agricultural management techniques more suitable to producing fruit of better quality, and awareness of the need for greater care in personal hygiene and first aid training. Data analysis found that, to carry out the export strategy, companies had to seek the development and improvement of their manpower, with the secondary gain of improvement of their production processes, including those involving fruits that are directed to the Brazilian market, which also showed an improvement in quality.

Keywords: Fruits Exportation; Learning Process; Strategy in SME. 


\section{APRENDIZAJE Y ADECUACIÓN DE LAS OPERACIONES PARA LOGRAR ESTRATEGIAS DE EXPORTACIÓN EN LAS PYMES}

\section{RESUMEN}

En este artículo se presenta un estudio del desarrollo tecnológico que ocurre en asociación a los procesos de aprendizaje en las micro y pequeñas empresas exportadoras de frutas. El objetivo es responder a la siguiente pregunta: ¿cómo las PyMEs frutícolas adecuan sus operaciones para realizar la estrategia de exportación? Para buscar respuestas, se realizó una investigación cualitativa de estudio multi-caso, en la cual fueron estudiadas cuatro empresas. Los datos fueron recolectados a través de entrevistas semi-estructuradas y en profundidad. Para garantizar la calidad de las exportaciones de frutas, existe un sello de certificación internacional llamado de Globalgap, que, una vez obtenido, permite superar las barreras de entrada de los productos en otros países. Tres de las cuatro empresas estudiadas tienen esta certificación. A lo largo del proceso de certificación, las empresas tuvieron que promover un intenso aprendizaje y cambios en sus rutinas de trabajo. Estos cambios implicaron en el uso de nuevas tecnologías, como es el caso del modo y del tipo de aplicación de fertilizantes y pesticidas químicos. Con el aprendizaje, ocurrieron procesos como la adquisición de nuevos conocimientos sobre las técnicas más adecuadas de manejo agrícola para producir frutas de mejor calidad, la concientización sobre la necesidad de un mayor cuidado en la higiene personal y entrenamiento en primeros auxilios. El análisis de los datos posibilitó concluir que, para llevar a cabo la estrategia de exportación, las empresas tuvieron que buscar desarrollo tecnológico y mejoras de su mano de obra, teniendo como ganancia secundaria la mejora de los procesos productivos, incluso para las frutas que son direccionadas al mercado brasileño, las cuales también mostraron una mejoría en la calidad.

Palabras-clave: Estrategia en las Micro y Pequeñas Empresas; Exportación de Frutas; Proceso de Aprendizaje. 


\section{INTRODUÇÃO}

A exportação de frutas é atividade que vem aumentando no âmbito do comércio internacional. Para aproveitar as oportunidades existentes e o cenário favorável dos países desenvolvidos que preferem importar frutas in natura, produtores de fruta precisam superar as barreiras de entrada impostas pelos países importadores. Essas barreiras residem basicamente em dois pontos: (i) mecanismos jurídicos internacionais de regulação baseados em normas de segurança alimentar e ambiental, e (ii) exigências do mercado consumidor de cumprimento de diretrizes de boas práticas sociais nas operações (que incluem os processos de trabalho), assegurando a qualidade de vida no trabalho da mão de obra envolvida na produção de frutas (Cavalcanti e Moreira, 2003).

O Brasil se destaca por sua força agrícola, tanto que em 2004, figurou na terceira posição da lista dos maiores produtores mundiais de fruta. As forças da fruticultura nacional são compostas por elementos como solo fértil, clima favorável e relativa vantagem de posicionamento geográfico em relação aos países de destino quando comparados com outros concorrentes mundiais, como China, Indonésia, Argentina e Peru (Oliveira, 2005; Anuário Brasileiro da Fruticultura, 2009).

Os principais mercados para onde é destinada a produção brasileira de frutas são os países da União Europeia, Estados Unidos e Canadá. Esses países, considerados os maiores consumidores de fruta, no entanto não possuem força agrícola interna capaz de atender toda sua própria demanda, fazendo com que países com melhores condições agrícolas se movimentem para atendê-los (Silva, 2007).

No entanto, o país pode explorar mais a exportação de frutas, uma vez que o Brasil não chega a exportar $2 \%$ de sua produção. No aumento das exportações nacionais, as micro e pequenas empresas (MPE) fruticultoras podem desempenhar um papel relevante, mas depois de atender os pré-requisitos para tanto, dos quais dois são: obter a certificação Globalgap e modernizar seus processos de produção para adequarem-se às exigências internacionais. Isso é desafiante, pois o padrão de qualidade exigido pelo mercado brasileiro, que, normalmente, elas estão adaptadas, é menos rigoroso do que o do mercado internacional de frutas. Para exportar, as MPE fruticultoras precisam passar por intensos processos de aprendizagem e de melhoria de sua tecnologia produtiva (Ibraf, 2010).

A exportação de frutas é muito relevante para as regiões produtoras em relação aos aspectos de desenvolvimento regional e social. Quanto ao desenvolvimento regional, as empresas fruticultoras, normalmente, não se encontram próximas a grandes centros, onde há empresas industriais ou prestadoras de serviços. A fruticultura apresenta oportunidades para a geração de 
empregos em regiões onde há pouca oferta de trabalho e pouco desenvolvimento econômico. Quanto ao aspecto social, a fruticultura não demanda mão de obra com elevado nível de qualificação técnica; pelo contrário, empresas fruticultoras preferem capacitar seus funcionários de acordo com suas necessidades. Por isso, a fruticultura tem condições de acolher trabalhadores que não seriam contratados por outros segmentos empresariais que demandam níveis mais elevados de qualificação (Silva, 2007).

Isso posto, o objetivo desse artigo é responder a seguinte pergunta: Como as MPE fruticultoras adequam suas operações para realizar a estratégia de exportação? Para responder essa pergunta, houve especial interesse em analisar processos de desenvolvimento de novas tecnologias de produção e de aprendizagem.

\section{FRUTICULTURA E EXPORTAÇÃO}

As empresas fruticultoras têm ganhado espaço no cenário do comércio mundial. O apelo por hábitos alimentares mais saudáveis, incluindo o consumo de frutas in natura, é um dos motivos que explica o aumento das exportações de frutas. $\mathrm{O}$ montante monetário das exportações de frutas em nível mundial mais do que dobrou no período entre 1985 e 1995, saindo do valor de US\$7,7 bilhões para US\$ 17 bilhões. Para o Brasil, isso representa oportunidades de novos negócios, uma vez que o território nacional oferece solo fértil e clima favorável para a produção de frutas. Um exemplo é a região do Vale do Rio São Francisco, mais especificamente no pólo fruticultor dos municípios de Petrolina - PE e Juazeiro - BA, onde é possível colher mais de duas safras anuais. As principais frutas exportadas pelo Brasil são: abacaxi, banana, laranja, maçã, mamão, manga e uva (Cavalcanti e Moreira, 2003; Silva, 2007).

O Brasil faz parte do rol dos grandes produtores mundiais de frutas com a Índia, Indonésia, Estados Unidos, Espanha, Itália, Turquia, México e China. Em 2004, o país figurou na terceira posição, atrás de China e Índia (Oliveira, 2005). O principal destino das frutas brasileiras é a União Europeia que, em 2008, absorveu 76\% do volume exportado. Em termos de volume financeiro, a exportação de frutas brasileiras mostrou uma curva ascendente; de 1996 a 2003, oscilou na faixa de US\$ 300 milhões a US\$ 600 milhões, atingindo a faixa dos US\$ 700 milhões em 2008 (Oliveira, 2005; Anuário Brasileiro da Fruticultura, 2009). Contudo, a maior parte da produção nacional é direcionada para o mercado interno. Por isso, a presença brasileira no mercado internacional de frutas é pequena; do total das exportações de frutas há apenas $1 \%$ de exportações brasileiras (Cavalcanti e Moreira, 2003). 
Uma das barreiras de entrada no mercado internacional que impede o aumento das exportações do Brasil refere-se ao emaranhado de mecanismos de regulação fitossanitária. Esses mecanismos buscam salvaguardar a saúde dos consumidores de possíveis efeitos decorrentes do consumo de frutas contaminadas por pragas, doenças e defensivos. Os países que impõem a maior quantidade de regras para o trânsito de frutas são também os maiores importadores mundiais, quais sejam, os países da União Europeia, o Japão e os Estados Unidos. Outras barreiras de entrada são: exigências de qualidade mínima; acordos de privilégio para certas regiões, como no caso da exportação de bananas para a União Europeia, que privilegia algumas ex-colônias da América Central e África; importação limitada durante o período de safra local; imposição de preços mínimos para as importações; e obrigatoriedade de licença prévia para os importadores (Favaret Filho, Ormond e Paula, 1999).

O tema da sustentabilidade ambiental também figura na lista das barreiras enfrentadas pelo exportador de frutas. O tema emergiu na Conferência RIO 92. Na ocasião, foram firmados os primeiros acordos sobre a necessidade de certificação ambiental para os produtos agrícolas, com a finalidade de minimizar o impacto ambiental das operações. Atualmente, as frutas que não apresentam os rótulos referentes à qualidade para consumo e à sustentabilidade ambiental enfrentam mais dificuldades de inserção no comércio mundial (Oliveira, 2005).

Para auxiliar os produtores brasileiros a sobreporem essas barreiras para a exportação, órgãos do governo brasileiro, tais como a Empresa Brasileira de Pesquisa Agropecuária (Embrapa), o Ministério da Agricultura, Pecuária e Abastecimento (Mapa) e o Conselho Nacional de Desenvolvimento Científico e Tecnológico (CNPq), em parceria com os órgãos de representação dos produtores, desenvolveram o sistema de Produção Integrada de Frutas (PIF). Ele é baseado em normas e orientações elaboradas em comum acordo pelas entidades mencionadas. Essas normas estabelecem os pilares da organização da produção, da sustentabilidade do sistema e do monitoramento dos processos. Com elas, assegura-se que a produção de frutas seja realizada em conformidade com as exigências do mercado internacional, com especial atenção para o uso de fertilizantes e agrotóxicos, objetivando o mínimo de risco para a saúde do consumidor e para o meio ambiente. Isso provocou mudanças no campo de modernas tecnologias de produção, que repercutiram positivamente no aumento das exportações brasileiras (Oliveira, 2005; Silva, 2007; Souza e Amato Neto, 2007).

Ainda quanto ao PIF, pesquisas revelaram sua importância para a integração entre os agentes públicos e privados envolvidos no processo de exportação de frutas, por ele gerar os seguintes benefícios: $(i)$ possibilitar que as fases de produção, embalagem e transporte ocorram de 
forma sincronizada; (ii) facilitar o atendimento mais rápido das exigências do mercado internacional quanto à exportação; (iii) facilitar o atendimento de necessidades financeiras e técnicas assim como a melhor estruturação dos elementos que compõem a rede de exportação (Silva, 2007; Souza e Amato Neto, 2007).

A integração entre agentes públicos e privados também proporciona a inserção de micro e pequenos produtores de frutas no comércio internacional. Baseando-se, principalmente, nas orientações do PIF, esses agentes transferem conhecimentos e fornecem suporte a esses produtores. Há, por vezes, a atuação do agente intermediário, que, em especial na exportação de frutas in natura, faz a ponte entre o varejista no mercado exterior e o produtor, de tal forma que a produção é realizada de maneira direcionada a atender demandas específicas do varejista. Por isso, o comércio varejista é considerado como um indutor de mudanças do processo produtivo, reverberando na qualidade da produção e nas ações realizadas no processo produtivo. Um exemplo são os supermercados ingleses, que realizam importações de uva e manga por intermédio de agentes. Os agentes procuram os fornecedores e produtos certos para atender as demandas específicas dos supermercados. Assim, os supermercados ganham poder de controle sobre a operação (Souza e Amato Neto, 2007; Souza e Amato Neto, 2009) e muitos pequenos produtores podem ser beneficiados.

Faveret Filho, Ormond e Paula (1999) explicam que as dificuldades enfrentadas pela fruticultura para exportação, inclusive para inserção de micro e pequenos produtores, estão na assimetria de informações. Os autores explicam que nem sempre o mercado externo provê aos produtores as informações necessárias sobre as características do público consumidor, podendo resultar na diminuição de exportações.

Para lidar com essa realidade, no Estado de São Paulo, existe o programa denominado "Fruta Paulista", promovido pelo Instituto Brasileiro de Frutas (Ibraf), em parceria com o Serviço Brasileiro de Apoio às Micro e Pequenas Empresas (Sebrae). O programa tem por finalidade melhorar a qualidade da produção de frutas com a implementação das rotinas de seu manual "Boas Práticas Agrícolas". Essas rotinas objetivam assegurar melhorias do sistema de produção nas seguintes esferas: (i) segurança alimentar, no tocante ao uso controlado e racional de defensivos; (ii) segurança social, objetivando que o trabalhador rural realize suas atividades em condições de salubridade - quanto a esse item, há também atenção em relação ao cumprimento da legislação trabalhista; e (iii) segurança ambiental, focada na correta destinação de resíduos e respeito à legislação ambiental. As “Boas Práticas Agrícolas” possibilitam às MPEs produtoras obter o selo de qualidade reconhecido internacionalmente chamado Globalgap. Produtores que detêm o selo conseguem exportar com maior facilidade, superando barreiras de entrada. O programa também 
promove ações de marketing internacional. Para tanto, patrocina viagens de produtores para feiras especializadas na Europa e realiza degustação de frutas em supermercados no exterior (Ibraf, 2010).

\section{APRENDIZAGEM E GESTÃo ESTRATÉGICA NAS MICRO, PEQUENAS E MÉdIAS EMPRESA}

Os proprietários-dirigentes são atores preponderantes e centrais na definição das características de uma micro, pequena ou média empresa. Essa relação estreita entre os dois sistemas, dirigentes e empresa, é confirmada por um grande número de pesquisadores, como, por exemplo, Castaldi (1986), Filion (1988, 2004), Lima (2004, 2010). Segundo Hafsi (1985), essa relação tende a não ser tão estreita nas grandes empresas. Para o autor, o dirigente da pequena empresa é um "administrador direto", pois ele tem "um conhecimento direto e íntimo da situação [de gestão]. Ele pode então enfrentar a incerteza e a ambiguidade utilizando sua experiência e sua intuição" (p. 6, tradução nossa), o que não é comum nas grandes organizações, nas quais a divisão do trabalho é, geralmente, maior.

A partir dessas considerações e de uma perspectiva sistêmica, a figura 1 (Lima, 2008) visa a representar a dinâmica das relações entre os diferentes níveis sistêmicos que caracterizam uma micro, pequena ou média empresa: o dirigente, os codirigentes (quando há mais de um proprietáriodirigente na empresa), a equipe de direção formada pelos codirigentes, o conjunto dos membros da organização e o contexto. Seu formato, quase radial, busca representar visualmente a irradiação das influências internas dos membros da organização, mas principalmente dos proprietários-dirigentes que são preponderantes e centrais nas micro, pequenas ou médias empresas. Essas influências definem, em grande parte, a forma e o conteúdo dos processos de aprendizagem, assim como os elementos de orientação estratégica (missão, visão, objetivos e metas) que motivam a gestão estratégica nessas empresas (Lima, 2004; Wyer e Mason, 1998). A figura é útil para se entender os processos estratégicos dessas empresas, que se constroem, em grande parte, pela aprendizagem de seus membros (sendo preponderantes os proprietários-dirigentes), assim como pelas relações deles entre si e com pessoas externas a ela.

Revista Ibero-Americana de Estratégia - RIAE, São Paulo, v. 10, n. 2, p. 159-180, mai./ago. 2011. 
Figura 1- Modelo das relações entre níveis sistêmicos nas micro, pequenas e médias empresas.

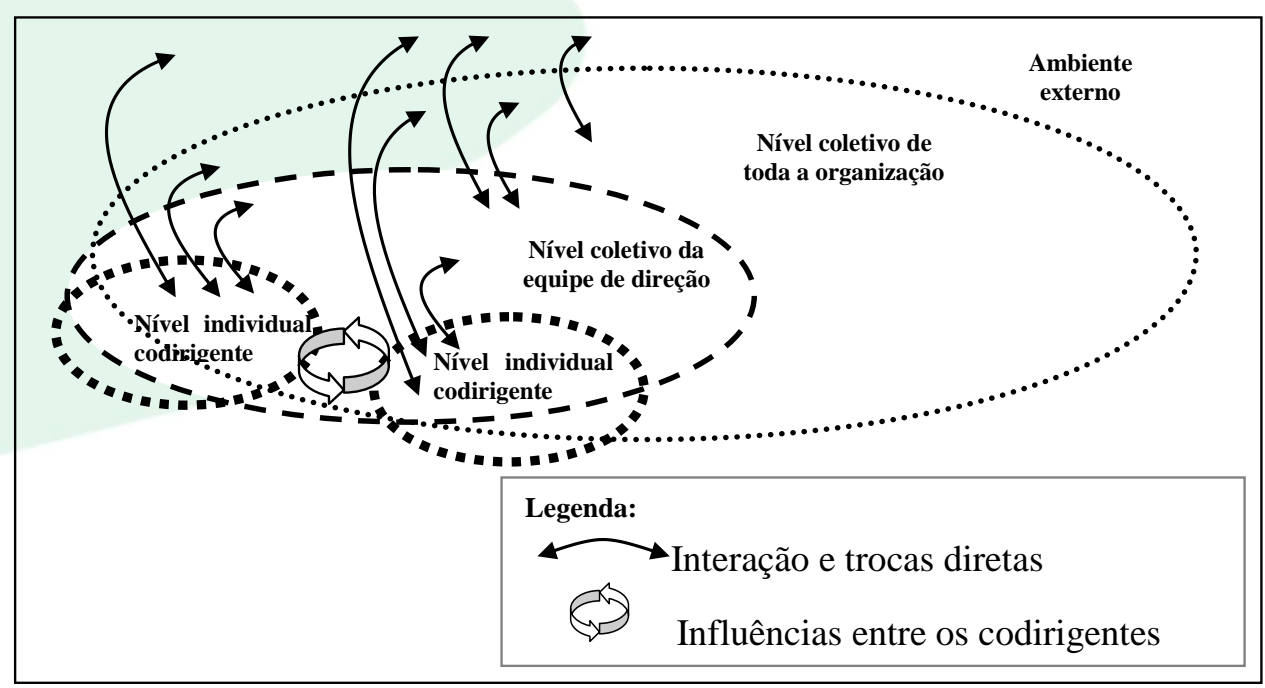

No modelo, quase radial (figura 1), um nível sistêmico interage com os outros de modo direto - o que é representado pelas flechas - ou de modo indireto pela mediação de um outro nível. Por exemplo, na obtenção de informações críticas com os empregados do nível hierárquico mais inferior realizada pelos dirigentes para a tomada de decisões estratégicas, o nível sistêmico individual dos dirigentes interage e aprende, direta e indiretamente, com o nível da coletividade de toda organização. A interação direta pela comunicação é representada pela flecha que liga diretamente os dois níveis, enquanto a indireta é a que ocorre por intermédio da equipe de direção cujas dinâmicas coletivas muito frequentemente são ativas no processo de obtenção de informações, de tomada de decisões estratégicas e de estabelecimento da visão compartilhada que define os rumos da empresa.

Na figura 1, o fato da representação dos níveis sistêmicos dos dirigentes e da equipe de direção não estarem completamente inseridos na representação do nível coletivo de toda a organização, busca refletir a realidade, visto que nem todas as dimensões da vida dos dirigentes e da equipe de direção são internas ao sistema da empresa. Por sua vez, a representação da influência mútua entre os dirigentes destaca o fato de que, nas relações internas entre os membros da empresa, cada dirigente é um dos principais stakeholders (Mitroff, 1983) definidores do pensamento do outro e da equipe de direção no que se refere à gestão estratégica e à administração da empresa em geral. 


\section{MÉTODOS DE PESQUISA}

A pesquisa realizada é do tipo exploratório, dada a falta de disponibilidade de conhecimento aprofundado sobre o tema estudado pelo fato de ela ser uma incursão inicial na abordagem do tema no contexto das MPEs brasileiras de fruticultura (Selltiz, Wrighstman e Cook, 2004). Ela é qualitativa e predominantemente indutiva, o que é oportuno, em razão dos impedimentos para se iniciar um estudo sobre esse tema no Brasil e se explorar a via dedutivista com hipóteses bem fundamentadas, tendo como base um corpo de conhecimento ainda incipiente.

Para Vieira (2004), a pesquisa qualitativa possibilita o levantamento de muitos dados em profundidade sobre uma amostra reduzida de unidades de análise, proporcionando a compreensão dos fatos da realidade social segundo seu contexto específico. Pesquisas cujo problema se inicia com as palavras "como" e "por que" devem ser, preferencialmente, realizadas com o método do estudo de caso (Yin, 2001). No estudo em questão, a pergunta de pesquisa foi do tipo "como".

Foram utilizadas como amostra quatro MPEs fruticultoras que exercem a atividade de exportação. A definição usada de MPE foi a de faturamento anual, segundo a Lei Federal 9.317/96, que classifica como microempresa aquela cujo faturamento anual é inferior a R \$ 240.000 e empresa de pequeno porte aquela cujo faturamento anual é superior a $\mathrm{R} \$ 240.000$ e inferior a $\mathrm{R} \$ 2.400 .000$ (Brasil, 2010).

Os dados foram coletados com entrevistas semiestruturadas realizadas com os proprietáriosdirigentes das MPE. Também foi possível realizar entrevistas com empregados. Além das entrevistas, foram feitas visitas a três das quatro empresas estudadas, o que viabilizou o acesso à fonte de evidência da observação direta (Yin, 2001).

As entrevistas foram gravadas e analisadas com auxílio do software Atlas.ti. A utilização desse tipo de software é pertinente no caso de investigações qualitativas por permitir ao pesquisador criar códigos e detalhar o estudo no momento da análise (Bandeira-de-Mello, 2006). A análise foi pautada pelas sugestões de Miles e Huberman (1994) relativas à identificação de aspectos peculiares de cada um dos casos que auxiliem a explicar o fenômeno estudado e a posterior comparação entre os casos, de modo a realizar as análises intra e intercaso. Na análise de cada uma das empresas da amostra, foram identificados quatro conjuntos de ação para a realização da estratégia de exportação das MPEs. As ações foram nomeadas segundo o conteúdo das entrevistas, levando-se em consideração os aspectos mais enfatizados pelos próprios proprietários-dirigentes e funcionários. A apresentação desses dados encontra-se na seção 5 abaixo.

Já na seção 6, é apresentada a análise intercaso, utilizando-se o recurso da metamatriz ordenada. De acordo com Miles e Huberman (1994), a metamatriz ordenada possibilita ordenar 
dados e identificar semelhanças e diferenças entre os casos. A metamatriz ordenada também serve como base para a análise e a discussão dos resultados.

\section{CASOS}

Antes de iniciar a apresentação dos quatro casos é importante esclarecer que, de acordo com a legislação brasileira, a pessoa física do produtor de frutas é equiparada à pessoa jurídica de sua empresa produtora. Sendo assim, a razão social de cada uma das empresas da amostra utiliza o nome da pessoa física do produtor rural - com exceção da última empresa da amostra, que se trata de uma empresa com dois proprietários-dirigentes, que são irmãos, e para a qual optou-se utilizar a denominação Irmãos Belone - IB.

\subsection{FRANCISCO TAKAHIRO YAMASHITA - FTY}

A FTY é uma MPE produtora de caqui, uva, atemoia (uma variedade híbrida da pinha), dekopon (uma variedade híbrida da ponkã) e também de legumes. Foi fundada em 1990; sua faixa de faturamento anual declarada é superior a $\mathrm{R} \$ 240.000,00$ e inferior a $\mathrm{R} \$ 2.400 .000,00$, o que a caracterizada como empresa de pequeno porte. A área da propriedade é de 42 hectares. É localizada no município de São Miguel Arcanjo, Estado de São Paulo. A empresa exporta suas frutas para Canadá e Europa. A FTY, para realizar a estratégia de exportação, fez mudanças em suas práticas organizacionais relativas aos seguintes itens:

1) Manejo diferenciado - As frutas embarcadas para o exterior recebem um tratamento diferenciado desde o momento em que se sabe que haverá demanda no mercado internacional, ou seja, meses antes da época de colheita. Isso possibilita que sejam empregados adubos e defensivos químicos diferentes dos normalmente utilizados para frutas produzidas para o mercado brasileiro, resultando em um melhor padrão de qualidade e de sabor.

2) Treinamento dos funcionários - Para realizar o manejo diferenciado, os funcionários são treinados para aplicarem técnicas de cultivo que, normalmente, não empregam. Essas técnicas foram ensinadas por técnicos agrícolas externos à empresa que prestam serviços para a associação rural da região. Na percepção dos funcionários, a fruta direcionada para o 
exterior deve apresentar melhor padrão estético, quando comparada com a do mercado nacional. Também, para atender as exigências do mercado internacional, os funcionários da empresa realizaram cursos de tratorista e primeiros socorros em unidade do Senai, próxima à propriedade. Nas entrevistas, os funcionários destacaram a atenção que precisam dispensar aos cuidados de higiene, como, por exemplo, sempre lavar as mãos antes e depois de realizar o manejo.

3) Adequação das instalações - A empresa precisou realizar mudanças em suas instalações para adequar-se aos padrões de qualidade de produção exigidos pelo mercado internacional. Para tanto, efetuou melhorias como a construção do depósito para coleta de resíduos de defensivos e de tanques para coleta da sobra de defensivos, além de uma proteção com telas no galpão no qual as frutas são armazenadas após a colheita.

4) Certificação Globalgap - Em 2008, a empresa aderiu ao programa "fruta paulista" (mencionado na seção 2) para obter o selo de certificação Globalgap, especificamente para sua produção de caqui. No entanto, não logrou êxito, em razão da falta de conformidade com a legislação nacional para o uso de defensivos agrícolas na produção de caqui. $\mathrm{Na}$ agricultura brasileira, para fins de segurança alimentar, existe uma regulamentação sobre o uso de defensivos que estabelece quais tipos de defensivo podem ser empregados no processo produtivo. A regulamentação também dispõe sobre os períodos de carência, ou seja, o tempo necessário para colher a fruta após a aplicação do defensivo. Essa legislação é válida para a produção de frutas destinadas ao mercado interno, mas as normas do Globalgap exigem que o produtor rural esteja também em conformidade com a legislação nacional brasileira. Esse descompasso, uma lacuna jurídica entre as normas do Globalgap, e a legislação brasileira foi um forte impedimento para a empresa obter a certificação.

\subsection{CLAUDIO SHOITI ITO - CSI}

A CSI produz uva, caqui, ameixa nectarina, atemoia e dekopon. Foi fundada em 1992. Sua faixa de faturamento anual declarada é inferior a $\mathrm{R} \$ 240.000,00$, o que a caracteriza como microempresa. A área da propriedade é de 50 hectares e localiza-se no município de Pilar do Sul, no Estado de São Paulo. Os países para os quais exporta são Canadá e países europeus. Para facilitar as exportações e o aumento delas, foram promovidas mudanças nessa empresa relativas aos seguintes aspectos:

Revista Ibero-Americana de Estratégia - RIAE, São Paulo, v. 10, n. 2, p. 159-180, mai./ago. 2011. 
1) Envolvimento do proprietário-dirigente - Com o início da atividade de exportação, houve uma mudança na rotina de trabalho do senhor Claudio Shoiti Ito. Ele se tornou diretor de exportação da associação agrícola local que faz a exportação das frutas que sua empresa produz e também dos demais associados. A partir de então, ele passou a ter contato direto com clientes estrangeiros, o que lhe possibilitou compreender melhor o comportamento e as preferências do consumidor estrangeiro. Desse contato, emergiu o interesse em realizar viagens ao exterior para participar de feiras e eventos ligados ao comércio internacional de frutas. O somatório dessas experiências resultam na percepção de que o consumidor estrangeiro, e em especial o consumidor europeu, valoriza mais o produtor de frutas quando comparado com o consumidor brasileiro.

2) "Dia de Campo" - Para adequar as técnicas de manejo da produção aos padrões internacionais, o proprietário-dirigente da CSI passou a participar sistematicamente do evento chamado "Dia de Campo". Nessa ocasião, técnicas de produção de frutas para exportação, em especial no tocante à adubação, aplicação de defensivos e poda, são ensinadas por um técnico agrícola japonês trazido ao Brasil pela associação agrícola local. Para a CSI, o "Dia de Campo" representa uma grande oportunidade para qualificar todo o seu quadro de funcionários.

3) Reorganização das rotinas de trabalho - O proprietário-dirigente da CSI admite que se viu obrigado a implementar novas rotinas para a realização das diferentes atividades da sua empresa como forma de obter a conformidade com as demandas impostas para se fazer exportação. Para tanto, passou a registrar com precisão as datas de aplicação de adubos e defensivos. Também reestruturou o sistema de adubação para produzir menos volume de frutas e passar a se concentrar na busca por qualidade e sabor. Isso também gerou ganhos secundários, como um melhor controle de estoque. Para o senhor Claudio Shoiti Ito, a adoção dessas práticas provocou também redução do custo de produção, pois evitou desperdícios.

4) Globalgap - A empresa obteve o selo no primeiro semestre de 2010 para sua produção de caqui. Para tanto, não recorreu ao apoio de órgãos externos, como o programa "Fruta Paulista”. Contribuíram para a obtenção da certificação mudanças jurídicas promulgadas no início de 2010 para solucionar a lacuna jurídica entre as normas do Globalgap e a legislação agrícola brasileira. 


\subsection{CARLOS AKIRA MORIOKA - CAM}

A CAM é produtora de uva, ameixa, caqui, lichia, ponkã, atemoia, dekopon, nêspera e também diversifica a produção com o plantio de eucalipto. Foi fundada em 1985. Sua faixa de faturamento anual declarada é superior a $\mathrm{R} \$ 240.000,00$ e inferior a $\mathrm{R} \$ 2.400 .000,00$, o que a caracteriza como empresa de pequeno porte. A área da propriedade é de 100 hectares. É localizada no município de Pilar do Sul, Estado de São Paulo. A CAM exporta para países da Europa e para o Canadá. As mudanças feitas na empresas para tornar viável a exportação foram relacionadas aos seguintes temas:

1) Desenvolvimento do planejamento formal - A ideia de exportação surgiu na CAM como uma opção estratégica de escoamento adicional da produção de caqui e para a diminuição da dependência do mercado interno. Na década de 1990, o proprietário-dirigente da CAM percebeu que havia muitos produtores de fruta plantando caqui e que dali a alguns anos (em média a árvore do caqui leva oito anos para produzir em larga escala) haveria uma grande oferta da fruta no mercado nacional. Assim, o senhor Carlos Akira Morioka, juntamente com outros produtores de caqui, realizou pesquisas em embaixadas e consulados e realizou viagens ao exterior com o intuito de conhecer novos mercados. E, com isso, começou a exportar caqui para a Europa em 2000;

2) Aumento da variedade de frutas - Para manter a atividade da exportação ao longo dos doze meses do ano, uma vez que a safra do caqui ocorre de março a maio, a CAM passou a cultivar outras variedades de fruta. Elas foram atemoia, uva, nêspera e ameixa. Nesse ponto, há uma peculiaridade, a espécie de ameixa cultivada para exportação é diferente da espécie cultivada para o mercado brasileiro. De acordo com as explicações do proprietário-dirigente da CAM, a preferência de sabor do consumidor brasileiro é diferente da do consumidor europeu.

3) Atribuição adequada de responsabilidades a trabalhadores homens e mulheres - A experiência com a exportação ensinou a direção da empresa que é preferível canalizar seletivamente as habilidades comuns a trabalhadores homens e mulheres respectivamente para atividades em que eles sejam mais eficientes. No manejo direto das frutas, como poda, adubação e colheita, são mulheres que realizam as tarefas. Entre os funcionários da empresa, existe a percepção de que essas tarefas demandam paciência e "mãos delicadas", sendo as 
mulheres mais recomendáveis para desempenhá-las. Os homens exercem funções como dirigir trator, capinar e aplicar defensivos.

4) Globalgap - Assim como a CSI, a CAM logrou êxito em obter o selo no primeiro semestre do ano de 2010 para sua produção de caqui. A empresa não recorreu a nenhum tipo de apoio de programas de incentivo para obter a certificação.

\subsection{IRMÃOS BELONE - IB}

A IB foi fundada em 1994 e é produtora, exclusivamente, de figo. O faturamento anual declarado é inferior a $\mathrm{R} \$ 240.000,00$, o que a caracteriza como microempresa. A área da propriedade é de 17 hectares. Está localizada no município de Campinas, no Estado de São Paulo. A IB é a única empresa da amostra com mais de um proprietário-dirigente. É dirigida pelos irmãos, Onivaldo e Cláudio Belone. Exporta figo para o Canadá e países europeus. Outra característica peculiar da empresa, em comparação com as demais da amostra, é o fato de ser a única empresa que tem a exportação como atividade exclusiva, ou seja, o figo que produz é todo direcionado para o exterior. Assim como as demais empresas da amostra, a IB promoveu mudanças para realizar a estratégia de exportação, enfocando, principalmente, os itens seguintes:

1) Desenvolvimento de técnicas próprias de adubação - Os proprietários-dirigentes da IB explicaram que, quando foi iniciada a exportação do figo, houve dificuldades no tocante à adubação. Isso ocorreu quando a empresa aderiu ao PIF, em 2002, objetivando obter informações para melhorar o manejo da produção e a qualidade do produto. Seus dirigentes tiveram a impressão de que os técnicos do PIF pouco conheciam sobre a cultura do figo. Diante dessa realidade, os dirigentes tiveram que promover a aprendizagem em sua própria organização para descobrir técnicas apropriadas de adubação. Fizeram experiências que resultaram em um sistema no qual são mesclados adubos de origem folhear, orgânica e química e que os levou à melhoria buscada.

2) Abertura de uma trade exportadora - Para aproveitar as oportunidades que emergiram com a exportação, os proprietários-dirigentes da IB abriram uma segunda empresa que tem por finalidade atuar como trade exportadora para exportar os figos que produzem, com os figos dos produtores vizinhos. Dessa forma, além de produtores, os irmãos Belone também atuam na intermediação comercial. 
Aprendizagem e Adequação das Operações para Realizar Estratégias de Exportação em Micro e Pequenas Empresas

3) Montagem de uma packing house - Para atuar como intermediários, os irmãos Belone construíram um galpão para embalar os figos produzido por eles e pelos produtores vizinhos, segundo as exigências do mercado internacional. Esse galpão é denominado packing house no meio da fruticultura. O processo de embalagem é composto pelas fases de limpeza, secagem e acondicionamento em caixas.

4) Globalgap - A empresa obteve o selo Globalgap no primeiro semestre de 2010 valendo-se do apoio do programa "Fruta Paulista".

\section{ANÁLISE INTERCASO}

Com base na apresentação dos casos desenvolvida na seção anterior, foi possível conceber a tabela 1, que contém a metamatriz ordenada de análise intercaso.

Tabela 1- Metamatriz ordenada de análise intercaso.

\begin{tabular}{|c|c|c|c|c|}
\hline CASO & CONJ. DE AÇÕES 1 & CONJ. DE AÇÕES 2 & CONJ. DE AÇÕES 3 & CONJ. DE AÇÕES 4 \\
\hline FTY & Manejo diferenciado. & $\begin{array}{l}\text { Treinamento dos } \\
\text { funcionários. }\end{array}$ & Adequação das instalações. & $\begin{array}{c}\text { Globalgap: } \\
\text { não teve sucesso. }\end{array}$ \\
\hline CSI & $\begin{array}{l}\text { Envolvimento do } \\
\text { proprietário-dirigente. }\end{array}$ & "Dia de Campo". & $\begin{array}{l}\text { Reorganização das rotinas } \\
\text { de trabalho }\end{array}$ & $\begin{array}{l}\text { Globalgap: obteve } \\
\text { sucesso. }\end{array}$ \\
\hline CAM & $\begin{array}{l}\text { Desenvolvimento do } \\
\text { planejamento formal. }\end{array}$ & $\begin{array}{c}\text { Aumento da variedade } \\
\text { de frutas. }\end{array}$ & $\begin{array}{l}\text { Divisão do trabalho } \\
\text { segundo o gênero dos } \\
\text { trabalhadores. }\end{array}$ & $\begin{array}{l}\text { Globalgap: obteve } \\
\text { sucesso. }\end{array}$ \\
\hline IB & $\begin{array}{l}\text { Desenvolvimento de } \\
\text { técnicas próprias de } \\
\text { adubação. }\end{array}$ & $\begin{array}{l}\text { Abertura de uma } \\
\text { "trade" exportadora. }\end{array}$ & $\begin{array}{l}\text { Montagem de uma } \\
\text { "packing house" }\end{array}$ & $\begin{array}{l}\text { Globalgap: obteve } \\
\text { sucesso. }\end{array}$ \\
\hline
\end{tabular}

Analisando a tabela, é possível verificar que as empresas, para realizarem a estratégia de exportação, seguiram caminhos estratégicos diferentes. Somente no conjunto de ações 4, é possível identificar uma completa convergência de iniciativas das empresas, que foi a tentativa de obtenção da certificação Globalgap, dado que ela, quando obtida, é um facilitador das exportações para todos os fruticultores. Outras diferentes ações apresentadas no quadro são relacionadas à busca das 
condições mínimas que asseguram a obtenção da certificação, o que mostra que o Globalgap, de fato, significou uma etapa para a exportação que levou as empresas a implementarem melhorias das operações.

Contudo, ao se analisar separadamente cada uma das ações empreendidas para cada empresa e compará-las com as demais, é possível identificar diferenças.

Em relação ao conjunto de ações 1, a CSI e a CAM demonstram um forte envolvimento dos proprietários-dirigentes para adquirir conhecimentos sobre os procedimentos formais necessários para exportar e sobre o perfil do consumidor estrangeiro. Por outro lado, os dirigentes das MPE FTY e IB apresentaram preocupações de ordem técnica direcionadas ao manejo. É possível verificar que a IB procurou desenvolver uma tecnologia própria em termos de adubação. Assim sendo, é possível afirmar que, no conjunto de ações 1, CSI e CAM se voltaram para processos de aprendizagem relativos ao ambiente externo, enquanto a FTY e a IB buscaram processos de aprendizagem ligados ao processo produtivo, ou seja, processos internos.

Para o conjunto de ações 2, o desenvolvimento de melhores práticas de manejo foi um ponto em comum entre as empresas FTY, CSI e CAM; segundo os interesses de seus dirigentes, a aprendizagem realizada e as melhorias implementadas a partir da aprendizagem foram direcionadas para aspectos internos da organização. A CSI e a CAM inovaram no processo de trabalho (mais especificamente no processo produtivo), a CSI reestruturando o sistema de manejo e a CAM diversificando a produção. Já na IB, a aprendizagem dos codirigentes se concentrou, por um lado, em aspectos do ambiente externo para aumentar as exportações - inclusive a partir da captação de figos a exportar junto a produtores vizinhos - e, por outro, em aspectos internos relativos à criação da trade exportadora.

Quanto ao conjunto de ações 3, todas as empresas empreenderam iniciativas de aprendizagem e de mudança direcionadas para aspectos internos da melhoria das operações. Destaca-se a divisão do trabalho segundo o gênero dos trabalhadores na CAM, o que gerou, efetivamente, melhoria da qualidade da produção e melhor desempenho nas exportações. Também se destaca a montagem da packing house da IB, que significou para a empresa uma grande inovação com o uso de novas tecnologias para exportar em maior quantidade e com mais qualidade.

No que concerne ao conjunto de ações 4, além do que já foi exposto anteriormente, é relevante lembrar que a obtenção ou não do certificado Globalgap pelas empresas dependeu não apenas do atendimento de pré-requisitos previstos nas regras de certificação, mas, em boa parte, da solução de uma lacuna jurídica - o que fugia do poder de ação dos dirigentes e das empresas. 
Aprendizagem e Adequação das Operações para Realizar Estratégias de Exportação em Micro e Pequenas Empresas

\section{DISCUSSÃO DOS RESULTADOS}

Chama a atenção, nos resultados, o fato de que três das quatro empresas da amostra lograram êxito em obter o selo Globalgap, sendo que a CSI e a CAM o fizeram valendo-se de recursos próprios, sem apoio de órgãos externos como o programa "Fruta Paulista" (Ibraf, 2010). Isso demonstra empenho e comprometimento com a estratégia de exportação. No caso da CAM, é possível identificar requintes de racionalidade e planejamento formal. A empresa se preparou para superar uma eventual saturação de oferta no mercado nacional a partir da visão estratégica de seu proprietário-dirigente relativa à diversificação da produção e à exportação.

Quanto a aprendizagens e integração de novas tecnologias ao processo produtivo, ao analisar as quatro empresas, foi possível verificar que, de fato, a estratégia de exportação gerou melhoria das operações e geração/aquisição de novos conhecimentos, corroborando o que diziam Silva (2007) e Souza e Amato Neto (2007). As quatro empresas tiveram que qualificar a mão de obra; no caso das empresas CSI, CAM e FTY, houve a busca por informações externas junto a técnicos especializados sobre adubação, uso de defensivos e poda. Destaca-se também a divisão de trabalho por gênero da CAM. Outro aspecto relevante refere-se à IB, que desenvolveu um sistema próprio de adubação, uma vez que seus proprietários-dirigentes não conseguiram obter dos técnicos agrícolas que consultaram inicialmente as informações apropriadas para o aperfeiçoamento da cultura de figo. Todos esses elementos reforçam a ideia de empenho e elevado comprometimento dos proprietáriosdirigentes das quatro empresas com a estratégia de exportação. Eles também evidenciaram que as MPEs fruticultoras são capazes de superar deficiências e fraquezas internas para aprimorar suas operações. Isso arrefece a ênfase dada pela literatura dominante à necessidade de atuação de órgãos governamentais como CNPq e EMBRAPA no sentido de estimular empresas fruticultoras a aprimorarem suas técnicas de manejo e, assim, exportarem (Oliveira, 2005; Silva, 2007; Souza e Amato Neto, 2007).

São importantes as contribuições dadas pelas MPEs estudadas para o desenvolvimento regional, particularmente nos casos da CAM e da CSI, ambas localizadas no município de Pilar do Sul, e da FTY, localizada em São Miguel Arcanjo. As duas cidades não apresentam atividades industriais e comerciais de destaque, o que faz com que o agronegócio seja fundamental nelas como gerador de emprego e renda.

Outros benefícios da fruticultura aparecem, de modo mais nítido, no caso da IB. A empresa é situada no município de Campinas, que concentra pólos industrias, comerciais e de serviços. Nesse contexto, a fruticultura apresenta uma oportunidade de emprego para a mão de obra de baixa escolaridade. 
As quatro empresas da amostra exportam para países do continente europeu e Canadá mostrando consonância com os trabalhos citados na seção 2, que apontaram os países da União Europeia como maiores consumidores da produção de frutas brasileiras (Oliveira, 2005; Anuário Brasileiro da Fruticultura, 2009). Isso se reforça com o pensamento do proprietário-dirigente da CSI, para quem o consumidor europeu dá mais valor à produção de frutas quando comparado ao consumidor brasileiro.

Analisando os esforços que as empresas despenderam para adequar seus respectivos processos produtivos aos padrões internacionais, que se são pautados pelas regras do Globalgap, é possível afirmar que, em termos gerais, seus dirigentes visualizaram oportunidades de negócio atrativas com a exportação. A partir daí, o desenvolvimento de sua visão estratégica em prol da exportação levou em conta as condições climáticas favoráveis de que as empresas dispõem nas regiões onde se encontram, em especial no tocante à cultura do figo e do caqui, como destacavam Cavalcanti e Moreira (2003) e Silva (2007).

Nota-se que essa visão foi compartilhada com o conjunto dos membros de cada MPE estudada como descreve a figura 1 desse artigo. Tal figura descreve os processos de aprendizagem organizacional e de compartilhamento da visão estratégica das MPEs como sendo regidos pela preponderância dos proprietários-dirigentes e sendo estreitamente vinculados às (e dependentes das) dinâmicas de relação entre as pessoas e os níveis sistêmicos relativos à MPE - o que inclui seu contexto (Lima, 2004, 2008, 2010).

Os processos de aprendizagem de tecnologias e modos de proceder que deram base à adequação das operações e à realização das estratégias de exportação nas MPEs também podem ser, em boa parte, descritos com auxílio do modelo da figura 1. A preponderância e a centralidade dos proprietários-dirigentes quanto à aprendizagem organizacional destacados no modelo se manifestam claramente nas MPEs estudadas. Isso se vê, por exemplo, no fato de que foram eles próprios que lideraram a aprendizagem para desenvolvimento, nas empresas, de tecnologias e modos de proceder ou foram aprendê-las para, em seguida, integrá-los às MPEs ao liderarem um processo mais amplo de aprendizagem organizacional. Esse processo mais amplo de aprendizagem promoveu a adequação das operações e assegurou a realização da estratégia de exportação nas empresas. Vê-se aqui um reforço da ideia já sustentada em trabalhos anteriores de que a aprendizagem que sustenta a gestão estratégica nas MPEs, incluindo o desenvolvimento dos elementos de orientação estratégica e a realização de estratégias, se nutre, em boa medida, da aprendizagem dos proprietários-dirigentes e, normalmente, é promovida, principalmente, por eles (Lima, 2004, 2008, 2010; Wyer e Mason, 1998). 
Aprendizagem e Adequação das Operações para Realizar Estratégias de Exportação em Micro e Pequenas Empresas

Diante do exposto, cabe responder sucintamente a questão de pesquisa apresentada na primeira seção deste artigo. As MPEs fruticultoras pesquisadas adequaram suas operações para realizar a estratégia de exportação, servindo-se da aprendizagem (desenvolvimento e aquisição de novos conhecimentos e adoção de novas técnicas), tendo sido crítica e preponderante a aprendizagem de seus proprietários-dirigentes. Os membros das empresas desprenderam energia e esforços para buscarem informações e aprimoramento, valendo-se de seus recursos próprios e contando com pouco ou nenhum auxílio de órgãos de apoio.

\section{CONSIDERAÇÕES FINAIS}

Essa pesquisa teve como objetivo investigar as adequações que as MPE fruticultoras estudadas implementaram em suas operações para realizarem a estratégia de exportação. Essencialmente, constatou-se que é central o processo de aprendizagem. Ele envolve questões ligadas ao ambiente externo e também ao ambiente interno das empresas, como aqueles relativos ao manejo da produção e à melhoria da organização interna, assim como aqueles ligados ao desenvolvimento tecnológico da adubação e do processo de embalagem.

Sobressaíram-se nos dados o elevado nível de empenho e de comprometimento dos membros das quatro empresas para realizarem a estratégia de exportação. Isso relativiza a literatura segundo a qual as MPEs teriam graves dificuldades para superar barreiras de entrada e iniciar negócios no estrangeiro. As quatro empresas da amostra, cada uma atuando em seu contexto, desenvolveram capacidades como planejamento formal, envolvimento com o negócio, desenvolvimento próprio de técnicas de adubação, aquisição de novas tecnologias e diversificação de produção para aglutinar o papel de produtor e, ao mesmo tempo, o de exportador de frutas. Os proprietários-dirigentes conduziram essas realizações segundo sua visão estratégica, pautada pela percepção de vantagens e oportunidades que a exportação oferece quando comparada à atuação apenas no mercado nacional. Essa percepção gerou uma energia motivadora que contribuiu para que as empresas promovessem saltos de qualidade na produção de frutas, uma vez que existe uma grande discrepância entre o padrão de qualidade exigido pelo mercado brasileiro quando comparado com o mercado internacional. 


\section{REFERÊNCIAS}

Anuário Brasileiro da Fruticultura (2009). Anuário Brasileiro da Fruticultura 2009. Santa Cruz do Sul: Editora Gazeta.

Bandeira-de-Mello, R. (2006). Softwares em pesquisa qualitativa, In: Godoi, C.; Bandeira-deMello, R.; Silva, A. (Orgs.). Pesquisa qualitativa em estudos organizacionais: paradigmas, estratégias e métodos (429-460). São Paulo: Saraiva.

Castaldi, R. M. (1986), An analysis of the work role of CEOs of small firms. American Journal of Small Business, 1(16), 63-64.

Filion, L. J. (2004) Operators and visionaries: differences in the entrepreneurial and managerial systems of two types of entrepreneurs. International Journal of Entrepreneurship and Small Business, 1(1/2), 35-55.

http://dx.doi.org/10.1504/IJESB.2004.005376

Filion, L. J. (1988) The strategy of successful entrepreneurs in small business: vision, relationships and antecipatory learning. Tese de doutorado, University of Lancaster.

Hafsi T. (1985) Du management au métamanagement : les subtilités du concept de stratégie. Gestion, février, 6-14.

Instituto Brasileiro de Frutas - IBRAF (2010). O Projeto Fruta Paulista. Recuperado em 28 de julho de 2010, de http://www.ibraf.org.br/frutassaude/frutaPaulista.asp

Lima, E. (2008). A gestão estratégica de pequenas e médias empresas segundo a abordagem da aprendizagem sistêmica. Gestão \& Planejamento, 9, 22-34.

Lima, E. (2010). As relações na gestão estratégica de PME dirigidas por equipes de direção. In: Gimenez, F.; Ferreira, J. M.; Ramos, S. C. (Orgd.). Empreendedorismo e estratégia de empresas de pequeno porte (239-250). Curitiba: Champagnat.

Lima, E. (2004) Équipe de direction, vision partagée et apprentissage dans le management stratégique de PME. Tese de doutorado (Programa conjunto de Ph.D. em Administração), HEC Montreal, Montreal. 2004. Recuperado em 20 de maio de 2007, de http://www.inf.furb.br/ dalfovo/EdmilsonLima/index.html

Miles, M.; Huberman, A. (1994). Qualitative data analysis: an expanded sourcebook. 2 ed., Thousand Oaks: Sage.

Mitroff, I. (1983). Stakeholders of the organizational mind. San Francisco, Jossey Bass. 
Aprendizagem e Adequação das Operações para Realizar Estratégias de Exportação em Micro e Pequenas Empresas

Oliveira, L. A. (2005). A importância das normas internacionais para o comércio da fruticultura brasileira. Dissertação de Mestrado apresentada na Escola Superior de Agricultura "Luiz de Queiroz", da Universidade de São Paulo, na Área de Concentração: Economia Aplicada, Piracicaba.

Selltiz, C., Wrightsman, L.; Cook, S. (2004). Métodos de pesquisa nas relações sociais. São Paulo: EPU, (4 ed.), 1.

Silva, J. G. (2007). A Integração e coordenação dos agentes públicos e privados na fruticultura irrigada no polo Petrolina-PE/Juazeiro-BA, visando o mercado global. Dissertação de Mestrado. Programa de Pós-graduação em Economia da Universidade Federal de Pernambuco, Recife.

Souza, R. C., Amato Neto, J. (2009). As transações entre supermercados europeus e produtores brasileiros de frutas frescas. Gestão e Produção, 16(3), 489-501.

http://dx.doi.org/10.1590/S0104-530X2009000300014

Vieira, M. (2004). Por uma boa pesquisa (qualitativa em administração). In. Zouain, D.; Vieira M. (Orgs.) Pesquisa qualitativa em administração(13-28). São Paulo: Editora FGV.

Wyer, P., Mason, J. (1998). An organisational learning perspective to enhancing understanding of people management in small businesses. International Journal of Entrepreneurial Behaviour and Research, 4(2), 112-128.

http://dx.doi.org/10.1108/13552559810224576

Yin, R. (2001). Estudo de caso: planejamento e métodos. (2. ed.) Porto Alegre: Bookman.

Recebido: 13/05/2011

Aprovado: 27/07/2011

Revista Ibero-Americana de Estratégia - RIAE, São Paulo, v. 10, n. 2, p. 159-180, mai./ago. 2011. 